\title{
Theoretical Investigation of Non-Linear Optical (NLO) Properties and UV- Visible Spectra of N-(3, 5-dichlorobenzylidene)aniline and N-(3, 5- dichlorobenzylidene)4-nitroaniline
}

\author{
Md. Saiful Islam ${ }^{1}$, Nusrat Mousume ${ }^{1}$, M. Mufazzal Hossain ${ }^{1}$, Mohammed A. Aziz ${ }^{2}$ and M. Saiful Islam ${ }^{2 *}$ \\ ${ }^{1}$ Department of Chemistry, Dhaka University, Dhaka-1000, Bangladesh \\ ${ }^{2}$ Department of Theoretical and Computational Chemistry, Dhaka University, Dhaka-1000, Bangladesh
}

(Received: 22 May 2018 ; Accepted : 2 July 2018)

\begin{abstract}
The non-linear optical properties of two Schiff bases, $N$-(3,5-dichlorobenzylidene)aniline (A) and $N$-(3,5dichlorobenzylidene)4-nitroaniline (B) have been studied by ab initio Hartree-Fock method using 6-311G (d,p) basis set. In this study, we report the dipole moment $(\mu)$, polarizability $(\alpha)$ and hyperpolarizability $(B)$ of both compounds. The hyperpolarizability (B) value of $\mathbf{B}$ is much greater than that of the compound $\mathbf{A}$ as it is expected because of the strong intramolecular charge-transfer interaction. The geometrical parameters of the optimized structure of both $\mathbf{A}$ and $\mathbf{B}$ are reported here and compared with the available experimental data of the relevant compounds. We also calculated the $\lambda_{\max }$ values of compounds $\mathbf{A}$ and $\mathbf{B}$. The UV-visible spectra show that both compounds are transparent in the visible region (> $400 \mathrm{~nm}$ ), implying non-zero microscopic hyperpolarizability. All calculations have been performed using GAUSSIAN09 programme.
\end{abstract}

Keywords: Non-linar optical (NLO) properties, Schiff base, UV-visible spectra, HF.

\section{Introduction}

Searching for new materials with non-linear optical (NLO) response is an important research area ${ }^{1}$. Research in this area involves design, synthesis and fabrication of materials exhibiting large second-order NLO response. Numerous compounds have been studied experimentally as well as theoretically ${ }^{2-6}$ because of its application in optical computing, telecommunications, optical signal processing, modulators and second harmonic generators ${ }^{7-10}$. Nowadays, the researcher are more interested to the NLO organic materials ${ }^{11,12}$ because conjugated organic compounds have large NLO response than traditional inorganic materials such as $\mathrm{LiNbO}_{3}{ }^{13}, \mathrm{KH}_{2} \mathrm{PO}_{4}{ }^{14}, \mathrm{LiB}_{3} \mathrm{O}_{5}{ }^{15}$ etc. Organic compounds for NLO applications have excellent environmental and thermal stability, high mechanical strength, low refractive indices and dielectric constants ${ }^{16}$. Organic compounds of NLO activity are generally consist of $\pi$-electron conjugated moiety substituted with an electron acceptor group on one end and electron donating group on the other end. Thus it generates a 'push-pull' conjugated structure ${ }^{17}$. Among organic compounds with NLO activity, Schiff bases are of special interest because of their large hyperpolarizability (ß) due to delocalization of the $\pi$-electron clouds $^{18-20}$.

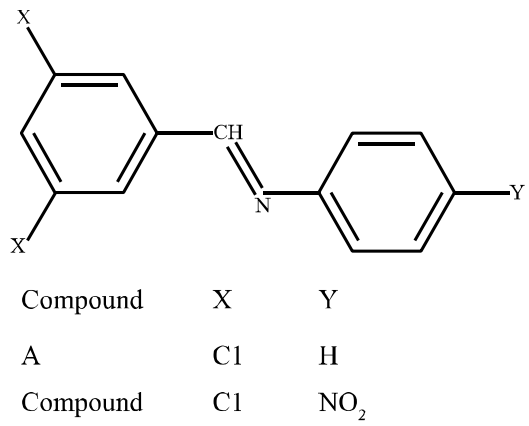

Fig. 1. Chemical structure of the compounds $\mathbf{A}$ and $\mathbf{B}$.
The aim of this study is to investigate the microscopic nonlinear response of a Schiff base $N-(3,5-$ dichlorobenzylidene)aniline (A) and $N-(3, \quad 5-$ dichlorobenzylidene)4-nitroaniline (B). In this paper, we present a theoretical investigation of the dipole moment $(\mu)$, polarizability $(\alpha)$, hyperpolarizability (B), electronic properties and UV spectra of the compounds $\mathbf{A}$ and $\mathbf{B}$ with acceptor substituent nitro group $\left(-\mathrm{NO}_{2}\right)$ at para position (B) and electron donating substituent chloro group $(-\mathrm{Cl})$ at meta position by ab initio Hartree-Fock method.

\section{Computational Method}

Geometries of the two compounds (A and B) were fully optimized at the $a b$ initio closed-shell restricted HartreeFock (HF) level using the 6-311G (d,p) basis set, where two polarization functions have been used. Geometry optimization was taken to be converged if the maximum force was smaller than 0.000045 hartree/ Bohr and no symmetry was imposed in the calculation. Electric dipole moment $(\mu)$, polarizability $(\alpha)$ and hyperpolarizability ( $(B)$ values were calculated at the same level of theory as this method was found to be appropriate for getting reliable trends in hyperpolarizability (B) values ${ }^{21,22}$. Electronically excited state calculations were performed on the optimized structure by Time-Dependent Density Functional Theory (TD-DFT) at the 6-311+G (d,p) basis set. All calculations were performed using GAUSSIAN $09^{23}$ programme.

The average linear polarizability $\langle\alpha\rangle$ of the compounds $\mathbf{A}$ and $\mathbf{B}$ is calculated using the following equation ${ }^{24}$

$$
<\alpha>=1 / 3\left(\alpha_{x x}+\alpha_{y y}+\alpha_{z z}\right)
$$

Values of the average linear polarizability, $\langle\alpha\rangle$ of the GAUSSIAN09 output file given in atomic units (a.u.), were converted into the electrostatic units $\left(1\right.$ a.u. $=8.6393 \times 10^{-33}$ esu). 
In this study, we report total hyperpolarizability, $\boldsymbol{\beta}_{\text {tot }}$ for the investigated molecules. The magnitude of the hyperpolarizability tensor is given by the following equation

$$
\boldsymbol{\beta}_{\text {tot }}=\left(\beta^{2}{ }_{x}+\beta_{y}^{2}+\beta_{z}^{2}\right)^{1 / 2}
$$

Where, $\beta_{\mathrm{xxx}}, \beta_{\mathrm{xxy}}, \beta_{\mathrm{xyy}}, \beta_{\mathrm{yyy}}, \beta_{\mathrm{xxz}}, \beta_{\mathrm{xyz}}, \beta_{\mathrm{yyz}}, \beta_{\mathrm{xzz}}, \beta_{\mathrm{yzz}}, \beta_{\mathrm{zzz}}$ are the hyperpolarizability tensor and the magnitude of the hyperpolarizability, $\beta$ is as follows ${ }^{24}$

$\boldsymbol{B}_{\text {tot }}=\left[\left(\beta_{\mathrm{xxx}}+\beta_{\mathrm{xyy}}+\beta_{\mathrm{xzz}}\right)^{2}+\left(\beta_{\mathrm{yyy}}+\beta_{\mathrm{yzz}}+\beta_{\mathrm{yxx}}\right)^{2}+\left(\beta_{\mathrm{zzz}}+\beta_{\mathrm{zxx}}\right.\right.$ $\left.\left.+\beta_{\mathrm{zyy}}\right)^{2}\right]^{1 / 2}$

The hyperpolarizability values are also converted into electrostatic units, which is given in the Gaussian output file in atomic units.

\section{Results and Discussion}

\section{Geometric parameters}

From the optimized structure of the two molecules, it is seen that, the molecules are non-planar (Figure 2). It is found from the compound $\mathbf{A}$ that, the two Schiff base moieties $((\mathrm{C} 1-\mathrm{C} 6, \mathrm{~N} 1)$ and $(\mathrm{C} 7-\mathrm{C} 13, \mathrm{Cl1}, \mathrm{Cl} 2))$ are inclined at an angle of $138.4^{\circ}$ and the compound $\mathbf{B}$, the two Schiff base moieties ((C1-C7, Cl1, Cl2, N1) and (C8-C13, N2, O1, $\mathrm{O} 2)$ ) are inclined at an angle of $134.3^{\circ}$.

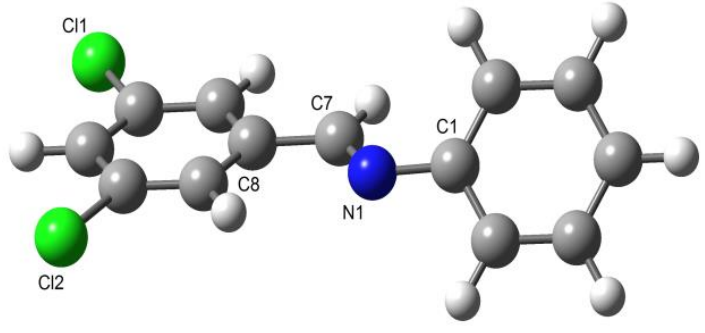

A

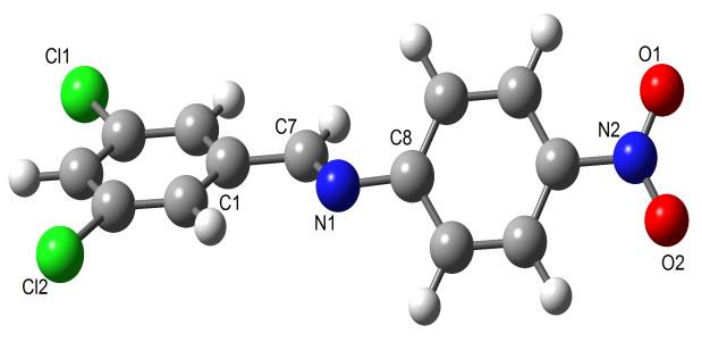

B

Fig. 2. The optimized molecular structure of the investigated compounds $\mathbf{A}$ and $\mathbf{B}$.

Selected bond lengths and bond angles of the optimized compounds $\mathbf{A}$ and $\mathbf{B}$ are given in the Table $\mathbf{1}$. Investigation of the bond length of the compounds $\mathbf{A}$ and $\mathbf{B}$ shows that the $\pi$-bonds are conjugated throughout the structure except for the N2-C11 bonds (for B). The N2-C11 bond connects the nitro $\left(-\mathrm{NO}_{2}\right)$ group with the phenyl ring. All the bonds (except N2-C11 and C-H bonds for B) show both $\pi$ and $\sigma$ - bond character. The $\mathrm{C}-\mathrm{C}$ bond lengths in the phenyl ring range from $1.375 \AA$ to $1.392 \AA$ (for $\mathbf{A}$ ) and $1.374 \AA$ to $1.392 \AA$ (for B) respectively. The C1-N1, C7-N1 and C7C8 (for A) and C8-N1, C7-N1 (for B) bond lengths are shorter than typical single $\sigma$ bonds. The $\mathrm{C}-\mathrm{Cl}$ bond lengths in the two compounds are longer than the single $\sigma$ bonds

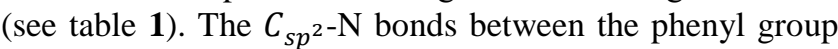
and nitro group are clearly single $\sigma$ bonds for $\mathbf{B}$. The C7-N1 bond length (1.251 $\AA$ ) of $\mathbf{A}$ and $\mathbf{B}$ compounds show a partial double bond character which is also an evidence for conjugation $^{25,26}$.

Table 1. Some selected bond lengths $(\AA)$ and bond angles $\left(^{\circ}\right)$ for the compounds $A$ and $B$

\begin{tabular}{|c|c|c|c|}
\hline \multicolumn{4}{|c|}{ Compound A } \\
\hline & & \multicolumn{2}{|c|}{ Bond length $(\AA)$} \\
\hline C1-N1 & 1.409 & \multirow[t]{4}{*}{$\mathrm{C} 7-\mathrm{C} 8$} & \multirow[t]{4}{*}{1.481} \\
\hline C7-N1 & 1.249 & & \\
\hline C10-Cl1 & 1.741 & & \\
\hline $\mathrm{C} 12-\mathrm{Cl} 2$ & 1.742 & & \\
\hline & \multicolumn{3}{|c|}{ Bond angle $\left(^{\circ}\right)$} \\
\hline C2-C1-N1 & 117.6 & N1-C7-C8 & 122.1 \\
\hline C6-C1-N1 & 122.9 & C9-C10-Cl1 & 119.4 \\
\hline C1-N1-C7 & 120.3 & C11-C10-C11 & 119.2 \\
\hline $\mathrm{C} 11-\mathrm{C} 12-\mathrm{Cl} 2$ & 118.7 & $\mathrm{C} 13-\mathrm{C} 12-\mathrm{Cl} 2$ & 119.5 \\
\hline \multicolumn{4}{|c|}{ Compound B } \\
\hline & \multicolumn{3}{|c|}{ Bond length $(\AA)$} \\
\hline C8-N1 & $\begin{array}{l}1.403 \\
1.416^{*}\end{array}$ & C11-N2 & 1.461 \\
\hline C7-N1 & $\begin{array}{l}1.251 \\
1.276^{*}\end{array}$ & $\mathrm{~N} 2-\mathrm{O} 1$ & $\begin{array}{l}1.187 \\
1.225 *\end{array}$ \\
\hline $\mathrm{C} 3-\mathrm{Cl} 1$ & 1.739 & $\mathrm{~N} 2-\mathrm{O} 2$ & $\begin{array}{l}1.187 \\
1.233 *\end{array}$ \\
\hline \multirow[t]{2}{*}{$\mathrm{C} 5-\mathrm{Cl} 2$} & 1.740 & & \\
\hline & \multicolumn{3}{|c|}{ Bond angle $\left({ }^{\circ}\right)$} \\
\hline C7-N1-C8 & 120.1 & $\mathrm{O} 1-\mathrm{N} 2-\mathrm{O} 2$ & 124.8 \\
\hline C1-C7-N1 & 122.3 & C4-C3-Cl1 & 119.3 \\
\hline C11-N2-O1 & 117.6 & $\mathrm{C} 4-\mathrm{C} 5-\mathrm{Cl} 2$ & 118.7 \\
\hline C11-N2-O2 & 117.6 & $\mathrm{C} 6-\mathrm{C} 5-\mathrm{Cl} 2$ & 119.6 \\
\hline C2-C3-Cl1 & 119.4 & & \\
\hline
\end{tabular}

*experimental values ${ }^{41}$

The bond lengths of C8-N1 and C7-N1 of the compound B found in this theoretical work agree well with the experimental value $^{41}$. C8-N1 bond length is $0.013 \AA$ which is $0.91 \%$ shorter than the experimental value, whereas C7$\mathrm{N} 1$ bond length is $0.025 \AA$, that is also $1.95 \%$ shorter than the corresponding experimental value.

\section{Linear and non-linear optical (NLO) properties}

Conjugated organic molecules containing both donor and acceptor may exhibit second-order NLO activity, because of strong donor-acceptor intramolecular charge transfer. 
The intramolecular charge transfer between two groups of opposite nature i.e., electron donor at one end and electron acceptor group at the other end of the dipolar organic molecules may have large hyperpolarizability values, a direct measure of NLO property. To design a new compound which may have high hyperpolarizabilities, one has to investigate the influence of donor-acceptor substituent position and the computational approach is the inexpensive way for this purpose before synthesis. In this study, we have investigated two compounds having only chloro groups at the one aromatic ring (compound $\mathbf{A}$ ) and containing donor chloro- in one ring and acceptor nitro group at the other aromatic ring (compound $\mathbf{B}$ ).

Table 2. Calculated electric dipole moments $(\mu)$ and dipole moment components of the compounds A and B

\begin{tabular}{ccccc}
\hline Compound & $\mu_{x}$ & $\mu_{y}$ & $\mu_{z}$ & $\begin{array}{c}\mu \\
\text { /Debye }\end{array}$ \\
\hline $\mathbf{A}$ & -0.71942 & -0.64499 & -0.04490 & 2.4585 \\
$\mathbf{B}$ & 1.62773 & -0.39931 & -0.03663 & 4.2610 \\
\hline
\end{tabular}

Electric dipole moment, hyperpolarizability and polarizability values are given in the table 2, 3 and 4 respectively. It is noticed that, compound $\mathbf{A}$ has only electron donor group $(-\mathrm{Cl})$ in one ring having no acceptor group but compound $\mathbf{B}$ contain an electron donor group ($\mathrm{Cl})$ in one ring and an electron acceptor group $\left(-\mathrm{NO}_{2}\right)$ in another ring. Thus, there should be a strong delocalization resulting high $\beta$ values. The hyperpolarizability $\left(\beta_{\text {tot }}\right)$, value of the compound $\mathbf{B}$ is much greater than the compound $\mathbf{A}$ (Table 3). Table $\mathbf{2}$ shows that, the electric dipole moment of the compound $\mathbf{B}$ is greater than that of compound $\mathbf{A}$. The higher dipole moment values are associated in general, with lager projection of $\beta_{\text {tot }}$ quantities ${ }^{27}$. The connection between the electric dipole moments of an organic compound having donor-acceptor substituents and hyperpolarizability is widely recognized in literature ${ }^{28,29,30-32}$.

Marder et al. ${ }^{33-36}$, worked on NLO properties of organic molecule and concluded that, the higher dipole moment value is related to higher $B$ values. In this study, it is obtained that the higher hyperpolarizability (B) value of $\mathbf{B}$ corresponds to higher dipole moment value. In this study it is found that, the polarizability $(\alpha)$ value of the compound $\mathbf{B}$ is slightly greater than that of the compound $\mathbf{A}$ and is shown in Table 4.
Table 4. Calculated $\alpha$ components at HF level using 6311G (d, p) basis set by GAUSSIAN09 for the compounds $A$ and $B$.

\begin{tabular}{ccccc}
\hline compound & $\alpha_{x x}$ & $\alpha_{y y}$ & $\alpha_{z z}$ & $\begin{array}{c}<\alpha>\mathrm{x} 10^{-30} \\
\text { /esu }\end{array}$ \\
\hline A & 253.18 & 166.57 & 83.06 & 1.45 \\
B & 282.25 & 174.44 & 93.54 & 1.58 \\
\hline
\end{tabular}

$U V$-visible spectroscopy

UV-visible spectral analysis can be used to predict the nonlinear optical properties of organic molecules after synthesizing the compound ${ }^{37}$. Computational method is an inexpensive and quicker tools to study the UV-visible spectral property of the organic compound even before synthesizing the compound. The UV-visible spectra and major transition of the two compounds, $\mathbf{A}$ and $\mathbf{B}$ are shown in Figure 3 and Table $\mathbf{6}$.

Albert et al. ${ }^{38}$ found that the correct substitutions of the donor-acceptor group in the porphyrin ring could produce high NLO responses. The donor-acceptor systems was characterized by strong intramolecular $\pi-\pi^{*}$ charge transition found through UV-visible spectral analysis. The NLO properties and UV-visible studies of push-pull ferrocene complexes containing hetero-aromatic rings in the conjugated chain were investigated by Thermal et al. ${ }^{39}$.

Electron absorption spectral studies in solution of compound, designed to possess NLO properties are important because of mainly to know the transparency region and the solvatochromatism. Zhou et al. ${ }^{40}$ have found the $\lambda_{\max }$ values for a large number of samples of novel paraphenylene alkynes macrocycles below $400 \mathrm{~nm}$. Compounds studied were transparent above $400 \mathrm{~nm}$ but hyperpolarizability values were higher.

The linear optical and NLO properties of donor-acceptor substituted diazabutadiene and hexatriene were investigated in a combined theoretical and experimental study by Dworezal et al. ${ }^{41}$.

Karakas et $\mathrm{al}^{42}$ studied NLO properties by computational method and experimentally measured UV-visible spectra of substituted benzylideneaniline having electron donor group in one ring and electron acceptor group in other ring. The two compounds studied were found to have high $\beta$ values and did not show any absorption peaks above $350 \mathrm{~nm}$.

Table 3. Calculated $B$ components and $\beta_{\text {tot }}$ at HF level using 6-311G $(d, p)$ basis set by GAUSSIAN09 for the compounds $A$ and $B$

\begin{tabular}{ccccccccccccc}
\hline compound & $\beta_{\mathrm{xxx}}$ & $\beta_{\mathrm{xxy}}$ & $\beta_{\mathrm{xyy}}$ & $\beta_{\mathrm{yyy}}$ & $\beta_{\mathrm{xxz}}$ & $\beta_{\mathrm{xyz}}$ & $\beta_{\mathrm{yyz}}$ & $\beta_{\mathrm{xzz}}$ & $\beta_{\mathrm{yzz}}$ & $\begin{array}{c}\beta_{\mathrm{zzz}} \\
\beta \mathrm{xx} 10^{-30} \\
\text { /esu }\end{array}$ \\
\hline $\mathrm{A}$ & 213.01 & -76.81 & -69.09 & -51.41 & -31.02 & 7.56 & -11.84 & -11.99 & -4.98 & 2.27 & 1.66 \\
$\mathrm{~B}$ & -828.73 & -136.12 & 16.78 & -33.71 & -35.65 & -53.02 & -16.56 & 57.78 & -2.57 & 3.56 & 6.69 \\
\hline
\end{tabular}




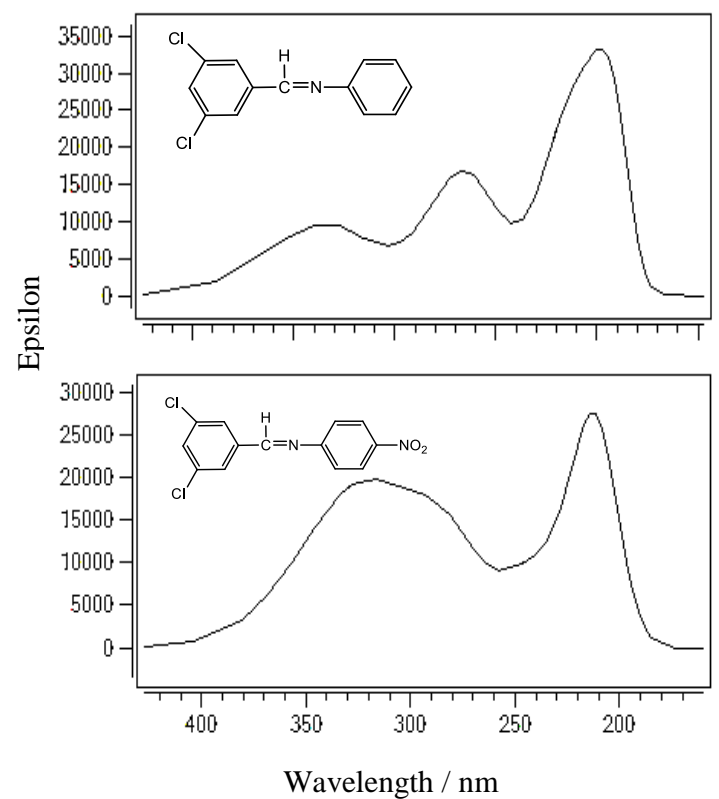

Fig. 3. Computational UV-visible absorption spectra of the compounds $\mathbf{A}$ and $\mathbf{B}$.

Table 5. The dipole moment $(\mu)$, linear $(\alpha)$ and nonlinear (B) polarizability, band gap $(\Delta E)$, and maximum wavelength $\left(\lambda_{\max }\right)$ of the compounds $A$ and $B$.

\begin{tabular}{cccccc}
\hline Compound & $\mu /$ Debye & $\begin{array}{c}<\alpha>\mathrm{x} \\
10^{-30} / \mathrm{esu}\end{array}$ & $\begin{array}{c}\beta \times 10^{-30} \\
\text { /esu }\end{array}$ & $\Delta \mathrm{E} / \mathrm{eV}$ & $\lambda_{\max } / \mathrm{nm}$ \\
\hline $\mathbf{A}$ & 2.46 & 1.45 & 1.66 & 2.250 & 335.6 \\
$\mathbf{B}$ & 4.26 & 1.58 & 6.99 & 2.211 & 329.2 \\
\hline
\end{tabular}

The calculated $\beta$ value of one compound is much higher and the experimentally observed $\lambda_{\max }$ value is smaller, whereas, for another compound, calculated $\beta$ value is lower and experimentally observed $\lambda_{\max }$ is larger. The relation between the hyperpolarizability ( $(\beta)$ value and $\lambda_{\max }$ of two compounds found in this work by computational method agrees well qualitatively with the results of Karakas et $\mathrm{al}^{41}$. Compound $\mathbf{A}$ has smaller $\beta$ value but the $\lambda_{\max }$ value is larger whereas compound $\mathbf{B}$ has higher $\beta$ value with the smaller $\lambda_{\max }$ value. The $\lambda_{\max }$ value of the compound $\mathbf{A}$ found in this work by computational method is larger $(20 \mathrm{~nm})$ than the experimental value. This discrepancy is probably because of solvatochromism as the experimental measurement of $\lambda_{\max }$ is done in solution.

Table 6. The maximum absorption wavelengths and molar extinction coefficients respectively, obtained from the UV-visible spectral analysis of the compounds $A$ and $B$ in gas phase.

\begin{tabular}{ccc}
\hline Compound & $\lambda / \mathrm{nm}$ & $\varepsilon / \mathrm{M}^{-1} \mathrm{~cm}^{-1}$ \\
\hline A & 335.6 & 10000 \\
B & 329.2 & 18500 \\
\hline
\end{tabular}

Both compounds studied in this work do not show any absorption above $400 \mathrm{~nm}$ (Figure 3), therefore both are transparent above $400 \mathrm{~nm}$ region.

Table 7. Calculated HOMO-LUMO energy (eV) and band gap $\left(E_{g}\right)$ of the compounds $A$ and $B$.

\begin{tabular}{cccc}
\hline Compound & $\begin{array}{c}\text { HOMO } \\
/ \mathrm{eV}\end{array}$ & $\begin{array}{c}\text { LUMO } \\
/ \mathrm{eV}\end{array}$ & $\begin{array}{c}\text { Band gap } \\
/ \mathrm{eV}\end{array}$ \\
\hline $\mathbf{A}$ & -8.365 & -6.115 & 2.250 \\
$\mathbf{B}$ & -8.365 & -6.154 & 2.211 \\
\hline
\end{tabular}

\section{Conclusion}

Dipole moment, polarizability and hyperpolarizability values of the compound $\mathbf{B}$ are much greater than those of $\mathbf{A}$. This higher $B$ value of $\mathbf{B}$ can be linked with the strong donor-acceptor intramolecular charge transfer interaction as this compound $\mathbf{B}$ has electron donor $-\mathrm{Cl}$ group at one end and an electron acceptor $-\mathrm{NO}_{2}$ group at the other end of the molecule. The NLO properties of organic compound are associated with the larger $\beta$ values. UV-visible spectra of both compounds show that, the maximum absorption takes place in the UV regions and the compounds are transparent in the visible region. It can be concluded that the compound B may exhibit microscopic NLO behavior. From the optimized structure, it is seen that both compounds are nonplanar and selected geometric parameters are in good agreement with the available experimental values of the relevant compounds.

\section{References}

1. Burland D.M., R.D. Miller, C.A. Walsh, 1994. Chem. Rev. 94, 31.

2. Karakaş A., A. Elmali, H. Ünver, H. Kara, Y. Yahsi, Z. Naturforsch, 2006. 61b, 968.

3. Ünver H., A. Elmali, A. Karakaş, H. Kara, E. Donmez, 2006. J. Mol. Struct. 800, 18.

4. Pedersen K., T.G. Pedersen, T.B. Kristensen, P. Morgen, 1999. Appl. Phys. 68, 637.

5. Perpète E.A., J.M. Andrè, B. Champagne, 1998. J. Chem. Phys. 109, 4624.

6. Bishop D.M., J.M. Luis, B. Kirtman, 1998. J. Chem. Phys. 108, 10013.

7. Pedersen T.G., K. Pedersen, P.K. Kristensen, J. Rafaelsen, N. Skivesen, Z. Li, S.V. Hoffmann, 2002. Surf. Sci. 516, 127.

8. Elmali A., A. Karakaş, H. Ünver, 2005. Chem. Phys. 309, 251.

9. Karakaş A., H. Ünver, A. Elmali, I. Svoboda, Z. Naturforsch, 2005. 60a, 376.

10. Karakaş A., A. Elmali, H. Ünver, I. Svoboda, 2004. J. Mol. Struct. 702, 103.

11. Marder S.R., B. Kippelen, A.K.Y. Jen, 1997. Peyghambarian Nature, 388, 845.

12. Burzynski R., M.K. Cassterens, Y. Zhang, 1996. Opt. Eng. $35,443$. 
13. Boyd G.D., R.C. Miller, K. Nassau, W.L. Bond, A. Savage, 1964. Appl. Phys. Lett. 16, 1856.

14. Smith W.L.O., Appl. Opt., 1977. 16, 798.

15. Chen C., B. Wu, A. Jiang, G. You, 1985. Sci. Sin. Ser. 28, 235.

16. Prasad P.N., D.J. Williams, 1991. Introduction to Nonlinear Optical Effects in Molecules and Polymers, John Wiley \& Sons, New York.

17. Garito A.F., K.Y. Wong, O. Zamani-Khamiri, 1987. Nonlinear optical and electroactive polymers, in: D. Ulrich, P. Prasad (Eds.), Plenium, New York.

18. Bhat K., K.J. Chang, M.D. Aggarwal, W.S. Wang, B.G. Penn, D.O. Frazier, 1996. Mater. Chem. Phys. 44, 261.

19. Karakaş A., A. Elmali, H. Ünver, I. Svoboda, 2004. J. Mol. Struct. 702, 103.

20. Ünver H., A. Karakaş, A. Elmali, 2004. J. Mol. Struct. 702 49.

21. Dehu C., F. Meyers, E. Hendrickx, K. Clays, A. Parsons, S.R. Marder, J.L. Brèdes, 1995. J. Am. Chem. Soc. 117, 10127.

22. Meyers F., J.L. Brèdes, J. Zyss, 1992. J. Am. Chem. Soc. 114, 2914.

23. Frisch M.J., G.W. Trucks, H.B. Schlegel, G.E. Scuseria, M.A. Robb, J.R. Cheeseman, V.G. Zakrzewski, J.A. Montgomery Jr., R.E. Stratmann, J.C. Burant, S. Dapprich, J.M. Millam, A.D. Daniels, K.N. Kudin, M.C. Strain, O. Farkas, J. Tomasi, V. Barone, M. Cossi, R. Cammi, B. Mennucci, C. Pomelli, C. Adamo, S. Clifford, J. Ochterski, G.A. Petersson, P.Y. Ayala, Q. Cui, K. Morokuma, D.K. Malick, A.D. Rabuck, K. Raghavachari, J.B. Foresman, J. Cioslowski, J.V. Ortiz, A.G. Baboul, B.B. Stefanov, G. Liu, A. Liashenko, P. Piskorz, I. Komaromi, R. Gomperts, R.L. Martin, D.J. Fox, T. Keith, M.A. Al-Laham, C.Y. Peng, A. Nanayakkara, C. Gonzalez, M. Challacombe, P.M.W. Gill, B. Johnson, W. Chen, M.W. Wong, J.L. Andres, C. Gonzalez, M. Head-Gordon, E.S. Replogle, J.A. Pople, GAUSSIAN98, Revision A.7, Gaussian, Inc., Pittsburgh, PA, 1998.

24. Thanthiriwatte K.S., K.M. Nalin de Silva, 2002. J. Mol. Struct. (Theochem), 617, 169.

25. Yang Q., Y. Tang, W. Yang, H. Chen, 1998. Acta Crystallogr. 54, 1532.
26. Wong M.S., V. Gramlich, F. Pan, C. Bosshard, P. Günter, 1997. Acta Crystallogr. 53, 757.

27. Lukes V., M. Breza, D. Vegh, P. Hrdlovic, V. Laurinc, 2003. Synth. Metals, 138, 399.

28. Prasad P.N., D.J. Williams, 1991. Introduction to Nonlinear Optical Effects in Organic Molecules and Polymers, Wiley, New York, USA.

29. Chemla D.S., J. Zyss (Eds.), 1987. Nonlinear Optical Properties of Organic Molecules and Crystals, Academic Press, New York.

30. Marder S.R., J.E. Sohn, G.D. Stucky (Eds.), 1991. Materials for Nonlinear Optics: Chemical Perspectives, ACS Symposium Series 455, American Chemical Society, Washington, DC.

31. Messier J., F. Kajar, P. Prasad, D. Ulrich (Eds.), 1989. Nonlinear Optical Effects in Organic Polymers, Kluwer Academic Publishers, Dordrecht.

32. Carters G., J. Zyss (Eds.), 1987. Nonlinear Optical Processes in Organic Materials, J. Opt. Soc. Am. 4.

33. Marder S.R., D.N. Beratan, L.T. Cheng, 1991. Science, 252, 103.

34. Risser S.M., D.N. Beratan, S.R. Marder, 1993. J. Am. Chem. Soc. 115, 7719.

35. Marder S.R., L.T. Cheng, D.N. Beratan, 1992. AIP Conf. Proc. 262, 252.

36. Marder S.R., L.T. Cheng, B.G. Tiemann, D.N. Beratan, 1991 Proc. SPIEInt. Soc. Opt. Eng. 1560, 86.

37. Kulakowska J., S. Kucharski, 2000. Eur. Polym. J. 36, 1805.

38. Albert I.D.L., T.J. Marks, M.A. Ratner, 1998. Chem. Mater. 10, 753 .

39. Justin Thomas K.R., J.T. Lin, Y.S. Wen, 1999. J. Organomet. Chem. 575, 301

40. Zhou Y., S. Feng, Z. Xie, 2003, Opt. Mater. 24, 667.

41. Dworczak R., W.M.F. Fabian, C. Reidlinger, A. Rumpler, J. Schachner, K. Zangger, 2002. Spectrochim. Acta: Part A 58 2135 .

42. Karakaş A., A. Elmali, H. Ünver, I. Svoboda, 2005 Spectrochimica Acta part A 61, 2979-2987. 
